\title{
Correction to: China's Reform and New Urbanization
}

\author{
Yining Li and Zhiqiang Cheng
}

\section{Correction to:}

Y. Li and Z. Cheng (eds.), China's Reform and New

Urbanization, https://doi.org/10.1007/978-981-16-4916-5

In the original version of the book, the reference number and citation were corrected. The chapter and book have been updated with the changes.

The updated version of these chapters can be found at https://doi.org/10.1007/978-981-16-4916-5_3

https://doi.org/10.1007/978-981-16-4916-5_6

https://doi.org/10.1007/978-981-16-4916-5_9 